\title{
Some Thoughts on the Role of the Critical Intellectual in Contemporary Germany
}

\author{
Erich Steiner, Universität des Saarlandes
}

\section{The Critical Intellectual as an Agent of Change in Contemporary German Culture $^{1}$}

In an attempt to relate the notion of the 'critical intellectual' to the notion of the 'agent of social change', we start from the usual reference of 'intellectuals' to a social grouping of writers, artists and scientists, who are often seen to be important shapers of public opinion through their prominent role in public discourse. They are seen as consciously acting agents, in contexts involving structural forces such as developments of technologies, forms of ownership and/or control of means of production, and access to power. The meanings of 'critical' may be more problematic, in that this term involves culturally very specific notions that we shall attempt to discuss in some more detail in section two. Our 'critical intellectuals,' then, form an interesting semantic field of potential agents of change. Regarding 'agents of change' as the superordinate term, we have a polyphyletic classification, based on the criteria of sex/gender, profession, spatial (dis-)location and cultural (dis-)location. Obviously, an individual may have multiple memberships of such criteria. Hence, the class of 'critical intellectuals' to be discussed here is a socio-cultural type, defined in culture-specific ways, acting in socio-economic

\footnotetext{
${ }^{1}$ I am very grateful to Feng Chongyi, Alberto Gil, Peter Godglück, Michael Halliday, Ruqaiya Hasan, Nicole Klingenberg, Leo Krämer, Elke Teich, Wolfram Wilss, and two anonymous referees, who have provided critical (in more than one sense) inputs to my remarks in this paper. None of these mentioned should be held responsible for anything that I have written here-because my own judgement and perspective have often prevailed over theirs.
}

Portal Journal of Multidisciplinary International Studies Vol. 2, No. 2 July 2005 ISSN: 1449-2490

http://epress.lib.uts.edu.au/journals/portal/splash/ 
contexts, and members may (or may not) be agents of change as determined by other criteria.

The term 'German' will be used to designate both a political and a socio-cultural context, which includes the former German Democratic Republic (GDR) and the Federal Republic of Germany (FRG) ${ }^{2}$; but in our examinations of current usage in section 2, we shall more generally consider publications in German. Germany is a nation-state, the political expression of economical and social systems to which the labels post-modern and consumer are frequently applied, in ways similar to other Western states. In a somewhat broader historical perspective, however, post-modern and consumer are cultural terms that denote current forms of expression for what continues to be a capitalist economy and a bourgeois democracy. Such basic properties still define essential aspects of the relationship of human beings to the means of production, as well as to each other; at the very least, the 'capitalist' aspect permeates all of socio-cultural space to a degree unprecedented in history. This is not to deny the heuristic value of notions such as postmodern and consumer, but it is to dispute claims that these types of societies represent something radically different from earlier capitalist ones, at least economically. Globalisation and internationalisation are more important and much more pervasive than ever-but they are not something ‘qualitatively new’ in human history (Hopkins, 2003). One of the overriding questions for this paper, then, will be whether under such conditions the concept of the 'the critical intellectual' is still a plausible one, whether it has changed over the past decades, and what the critical intellectual's role might be. ${ }^{3}$

\footnotetext{
${ }^{2}$ A very insightful discussion can be found in the online version of the Internationales Archiv für Sozialgeschichte der deutschen Literatur, see http://iasl.uni-muenchen.de (accessed 5 May 2003) for a discussion of writers as critical intellectuals in these two contexts since 1945 see Emmerich 2001, for East Germany in particular, see Mittenzwei 2001.

${ }^{3}$ In what I am going to suggest here, I am writing not as someone whose usual academic pursuit is to elucidate such notions as 'intellectual', 'critical', 'change agent' and so on. My own background was originally in English and German Philology, with subsequent specialisations in linguistics, computational linguistics and translation studies. I have thus been involved, over the years, in investigations into the workings of language and texts, often on micro-levels (Steiner 1991), sometimes in technological applications, such as machine translation and multilingual text generation (Steiner et al. 1988), and also in teaching students and researchers in the area of translation and multilingual text production (Steiner and Yallop. 2001). My main expertise is thus in the area of the micro-level realization of discourse, that is lexis and grammar, rather than in the area of the more macro-levels, such as would be the province of literary
} 
There is yet another sense in which 'being critical' enters into not only the contextualisation of our activities in everyday research and development, but into that activity itself: the crucial agencies of development and power have their home and enter into interaction with each other in crucial contexts of production in a society. And it is there that the critical agent has to meet them and engage with them, and not only in discourses about those contexts. I shall thus attempt to illustrate in section 3 how 'being critical' may translate into everyday productive activities in research and development, in my case linguistics and translation studies.

\section{The Meaning of Kritische(r) Intellektuelle(r)}

In an attempt to elucidate the meanings of the German phrase kritische(r) Intellektuelle $(r)^{4}$ we shall take two steps. The first will be an-extremely briefexploration of some important historical and philosophical contexts that gave and give meaning to the term. The second will be a consideration of patterns of current usage, relying on a large-scale electronic textcorpus of German and on the Internet as sources. The phrase kritische(r) Intellektuelle(r) will be used in German here to emphasise its cultural specificity, whenever this is judged necessary. We shall return to the English usage of 'critical intellectual' in section 3, once some of the specifics of the German meanings have been explored.

\section{$\underline{\text { Historical Contexts }}$}

Considering the development of the meanings of kritische( $r)$ Intellektuelle( $r)$ in a historical (geistesgeschichtlicher) perspective, we have to restrict ourselves to a global review of the etymology of the terms and of the history of some main strands of ideas,

studies, sociology or philosophy. However, the question of what it may mean to be an 'intellectual', and even more, to be 'critical', has often posed itself in explanations of what I believe to be a socio-cultural, rather than a technical, phenomenon - human language, and human discourses (Steiner 1985, 1996, 2000). And that question cannot be avoided even in in-depth micro-level investigations of language and text, if we accept the responsibility for what we are doing as researchers and teachers in our socio-cultural environments.

${ }^{4}$ In singular usage this term is most frequently used in the 'generic' masculine, which does have gender implications. 
mainly from the enlightenment onwards. Starting with Kritik as the noun from which kritisch is derived, we shall discuss its modern development, and some key concepts associated with it, most notably truth, human activity, and contradiction (Krings et al. 1973 Vol. 3, 807ff).

In (very roughly) pre-enlightenment texts, Kritik, the ability to engage in criticism, is associated with Bildung (education), rather than with a specialist knowledge and training in any one of the sciences. This finds its continuation in the more humanistically oriented post-enlightenment philosophy, as represented by Kant and the tradition deriving from his work, founded on an ethics of a reasonable, humane life. With the rise of the sciences, and scientific methodology in modern post-enlightenment times, the latter demanded the status of the Kritische Methode, often in opposition to the more rhetorically based classical meaning. For many scientists, being kritisch, for example in the sense proposed by Popper, is a method not connected to any ethics, except that of the scientific method itself. Twentieth-century Kritische Theorie (Adorno, Horckheimer, Habermas ${ }^{5}$ ) ) joins the humanistic line of reasoning in its criticism of a merely 'positivist' critical method, re-asserting the all important role of a 'reasonable social order' ('vernünftige gesellschaftliche Ordnung') that it derives from construing the course of history as the product of an economic process, or rather as an interplay between economic and sociocultural processes, following Marxist lines of reasoning. In this framework, Kritik is not merely method, but also something through which we can gain access to 'truth', or at least through which we can expose falseness.

Kritik in modern times is thus either a balanced judgement against a background of an assumed general education (humanism), or a scientific method, or a socio-political activity based on notions of 'progress and justice'. At least in the first and third of these readings, Kritik is always a process, in the course of which some state of affairs is judged relative to some (system of) norms, some ethics. It may be one of the specifically modern (in the sense of post-enlightenment) readings of Kritik that the norms themselves may

\footnotetext{
${ }^{5}$ For an overview see Habermas (1988).
} 
become objects of criticism, together with the acknowledgement of competing systems of norms, as in the works of influential, though very different writers, such as Hegel, Kant ('Kritik der reinen Vernunft, Kritik der praktischen Vernunft'), and Marx ('Kritik der politischen Ökonomie'). Criticism in older periods, therefore, is more often than not a criticism of authorities - but this may be less a change in the logic of the term, than a historically contingent fact. Also, and importantly for our context, Kritik usually sets out from an experience of contradictions and non-truths (Unstimmigkeit) in human activities or in states of affairs related to human activities. It is human activities that we criticise against a system of ethics, whereas we do not criticise natural processes, harmful though they may be. Kritik thus presupposes human freedom and choice in acting, and it presupposes responsibility and truth. This truth, however, can in modern times no longer be assumed to be given in one system of ethics and norms, but instead it is negatively defined as the avoidance of its opposite, of errors, of Falschheit through the critical process. Truth, although a presupposition of Kritik in a logical sense, is its result in the sense of the process. The meanings of 'critical' and 'concerned' as epithets of 'intellectual' in our current discussion are thus clearly related, but not synonymous: Being critical seems to be closely related to cognition, whereas being concerned may be largely related to affect and instinct. Just as both forms of existence and activity, the cognitive and the affective, are central to being human, and to the languages we know. The two qualities should not lose touch, although temporarily, there may be closer or weaker connections between them.

Having discussed some developments in the meaning of Kritik, and by implication kritisch, let us briefly consider the 'Intellektueller/Intellectual counterpart (mainly Ritter and Gründer, 1976 Vol. 4, 446ff). The Latin-based term is old, as is the Greek-based Kritik, but its modern meanings (adopted into German from French) are difficult to pin down, because they are partly ambiguous, partly vague. We shall use it here mainly as a sociological term, referring to a social grouping of Künstler, Wissenschaftler und Schriftsteller (artists, scientists and writers) who assume a public (öffentliche) and a critical (kritische) role in socio-culturally crucial discourses. In addition, the definition of 
the term 'intellectual' is often tied to the specialized creation and communication of symbolized knowledge. All the specialists whom we shall discuss in section 3, for example, are intellectuals in this sense, and they are all specialists concerned with symbolized knowledge, rather than with knowledge expressed in non-symbolic forms. But only some of them would be 'concerned' or even 'critical' intellectuals, and we shall try to give more specific meaning to these attributes in the following sections. A number of discursively recognized intellectuals will be named, and we shall discuss to what extent and in what sense they may or may not be specifically 'critical' intellectuals. For the specific academic field that will be discussed in depth in section 3-linguistics and translation studies - we shall specify a number of characteristics and features of their activities, which make them concerned (socially-oriented), critical, or else simply specialists. One implication will be that in the end, it is activities, more than individuals, that are 'concerned', 'critical' or otherwise. Indeed, most of us are variously critical or non-critical in different contexts at different times.

Before moving on to patterns of current usage, let us very briefly address the question of the relationship between critical intellectuals, in the sense just discussed, and the state. Historically, this is a changeable picture. Intellectuals have always been dependent on the socio-cultural subsystems that were able (and willing) to support them, because intellectuals as a group are only possible in societies that allow the creation and support of a relevant number of people freed from manual labour. The state, specifically, is a formation that is relatively recent, dating from Greek antiquity, at least in mainstream western historical writing. The nation-state of post-enlightenment times-and here we would definitely like to restrict ourselves to German history, in which the united nation state formally came into existence only in 1871 as a consequence of the Franco-German War of 1870/71 — has figured as a very changing environment for intellectuals. Occasionally and in parts of the nation, the state provided a home for them. More often, and particularly for critical intellectuals, it marginalised them, the extreme example being German fascism between 1933-45, when it was extremely difficult to be critical and not to be in exile or physically extinguished. Since the Second World War, and especially 
since the end of the 1960s, saw more freedom for critical intellectuals relative to the state, but very rarely with positive support of one for the other.

\section{Patterns of Current Usage}

Moving away from a diachronic perspective, let us now consider patterns of current usage, using a recent on-line debate on kritische Intellektuelle, then a large-scale electronic text corpus of German, and finally the Internet, as sources.

Scheideler (2002) has generalised the following leading topics about intellectuals out of current critical discourses in a recent online discussion forum: the intellectual as a discursive phenomenon; as the specialist for discourse and the intellectual community; as the voice of universal values; as the voice of ethics, morale; the writer as the prototypical intellectual; and, the end of the intellectual? ${ }^{6}$ Here several traditional concerns are reflected, but alongside new ones. also others that are partly new. There seems to be a tendency, even though much less prominent than in English post-modernist parlance, to emphasise the kritische(r) Intellektuelle(r) in discourses less as an individualised personality, and more as a type of voice. Another contemporary topic may be seen in the widespread and deeply rooted suspicion towards 'universal' values, although there is also a strong current of argumentation that regards exactly those values as essential for a critical perspective. And, arguably also typical of our times, the possibility of the kritische(r) Intellektuelle(r) is critically examined and questioned. If our entire culture and society is permeated by capital, and the value of everything is more than ever reduced to exchange value, rather than use value, and if furthermore all judgements are equally relative-with all sorts of 'differences' to be equally respected-how should there be any designated point of origin for a critical perspective?

From this structured and focussed debate in the Internationales Archiv für Sozialgeschichte der deutschen Literatur, let us move on to two less focussed, but at the

\footnotetext{
${ }^{6}$ Translated into English by the author, for the forum see Internationales Archiv für Sozialgeschichte der deutschen Literatur 2002, http://iasl.uni-muenchen.de, [accessed 2 January 2002].
} 
same time very representative, sources for explorations of the current meanings of our terms. Our source here is the Institut für deutsche Sprache’sGesamtkorpus geschriebener Sprache (full corpus of written language), which can be accessed at http://corpora.idsmannheim.de. In December 2001, when my searches in the electronic corpus were carried out, this resource held 374 million words, mainly from German language newspapers, including Swiss and Austrian publications, collected during the 1990s. In a search on 6 December 2001, we had 40 hits for the morphologically different variants of kritischer Intellektueller (4), kritische Intellektuelle (17), and kritischen Intellektuellen (19). Methodologically, we are opting here for precision, as we are demanding all and only the occurrences of the phrase as such. Our 'recall' is probably relatively weak in the sense that we are not getting any analytical occurrences, such as Intellektuelle, where the epithet 'kritisch' occurs somewhere else and/or in different morphological shape, in the same context. By way of comparison, Intellektuelle on its own received 1,597 hits in the same corpus.

The following are the topical contexts in which the terms occurred:

The critical intellectual versus.:

- practical politics (4)

- emotional public

- Stasi

- sublimation (Verdrängung) of the truth (2)

- market ideologies

- censorship

- general opinion

- right-wing politics

- globalisation,

- Kohl

- Arabic critical intellectuals vs. West

National groups of critical intellectuals:

- Serbian (3),

- Indonesian

- Kaundan

- Iranian 
- Nigerian

- GDR (2)

- Czeck opposition

Named Individuals:

- Althusser

- Enzensberger (3, but ambivalent)

- Habermas (2)

- Reemtsma

- Horckheimer

- Filip

- Gramsci, Barber

- Freud (Gisèle)

- Jelinek

- Grass

- Sarkuhi

- Walzer

- Drawert

- Bourdieu

Critical intellectuals are characterised as/ by:

- being weakened by the collapse of communism

- having vision of a better world (2)

- left-wing political leaning (2)

- supporting human rights

- having links with liberal media and elite in Germany

- a pursuit of truth.

In terms of current usage, then, kritische Intellektuelle are seen to be in opposition to political powers, among them market ideologies and globalisation. Specifically, they are seen in opposition to different types of political oppression, and there is a certain range of named individuals grouped under the term. Interestingly, among those names, Enzensberger is discursively positioned on the borderline between the critical intellectual and the merely public intellectual. Kritische Intellektuelle are also associated with visions of a just society, but not necessarily with the masses. It has to be noted, though, that the COSMAS corpus we have been using here largely consists of texts from the daily or weekly press, which partly explains the relative lack of philosophical depth of the field of discourse - this is not a criticism, but something quite predictable from the medium. For 
the same reason, in our forum in the Internationales Archiv für Sozialgeschichte der deutschen Literatur discussed above, a high level of philosophical expertise and specificity characterising the tenor of discourse-this is also quite predictable in terms of the medium and the participant relationships.

The third source used here is the Internet, where we conducted a Google-search on the full net on 2 January 2002. In this search, the data for the German search involves websites written in German, full text. We obtained 753 hits, which was almost 20 times the number obtained for the COSMAS corpus. It has to be emphasised, though, that we have no information about the size of the corpus at that time, except that the full multilingual search space would have been more than 2 billion websites. It is also interesting to note that we obtain many more results in a search allowing the spelling variants and intruding text between the two node words (approx. 7,800 on 2 January 2002). A comparative search for the English 'critical intellectual/ critical intellectuals' yields 2,157 hits in the more constrained search mode, many of which, especially in the case of 'critical intellectual,' were not in contexts involving the terminological meaning with which we are interested here. That number, not surprisingly, explodes to 935,000 in the less constrained research mode.

Returning to the German data, we noted in a fast and incomplete overview of the citations obtained that the main topics which we found in the COSMAS corpus are corroborated, although in much more breadth and detail. A substantial number of citations are, in fact, from discourses thematizing non-German intellectuals, e.g. Chomsky, Rorty, Bourdieu, Hobsbawm. In general, and in terms of level and specificity of expertise, we find a combination of relatively general-audience press discourses on the one hand, and of quite discipline-specific specialist debates on the other, due to the fact that the internet is used both by the general media and by scholarly and academic communities.

We would also like to quote here an Internet ranking of 'the 100 most important German public intellectuals’ (Frankfurter Allgemeine Sonntagszeitung (FAS) Nr. 4, 27. January 
2002, p.21) ${ }^{7}$. This count was about 'public', not necessarily 'critical' intellectuals. The method used was to count people writing in German, regardless of nationality, and excluding ‘journalists-only’ and 'writers-only’. Obviously, there are some methodological weaknesses here, because it is far from obvious what these categories mean exactly. Furthermore, this way of counting is not empirical in the sense that the names to be tested have to be chosen first, so that important intellectuals may not have entered the list simply because they were not considered candidates in the first place. This weakness does not apply to our own more truly bottom-up approach using Google, as we are counting all occurrences of the term kritische(r) Intellektuelle(r)_although this method also has its own problems of recall: we may miss occurrences of names simply because they do not occur in the neighbourhood of these phrases. Still, the ranking in the FAS is interesting enough to deserve at least a mentioning of the top ten names, which are (in this order): Günter Grass, Jürgen Habermas, Rudolf Augstein, Joseph Ratzinger, Peter Handke, Hans Magnus Enzensberger, Ulrich Beck, Christa Wolf, Maertin Walser and Marcel Reich-Ranicki. The first of these had 18,297 hits, the tenth 6,534 (measured as an average value between Google and Alltheweb searches). Johann Wolfgang von Goethe, by comparison, scores an average of 425,885 . In terms of profession, we find among the first 10: writers (5), a philosopher (1), a journalist-editor (1), a cardinal (1), a sociologist (1) and a literary critic (1).

\section{Linguistics and Natural Language Technologies as a Critical Context}

We have above given a sketch of some of the meaning(s) of kritische(r) Intellektuelle(r) in philosophical, literary and historical discourses (geistesgeschichtlich), and we also have attempted to trace some of the current usages and thematic configurations in which the term surfaces. One of the developments that we can see in such considerations is that whereas in earlier periods, say during and before the middle ages, intellectuals, and notably 'critical' intellectuals, were usually writers, artists and theologians/ philosophers, it may be considered to be typical of modernity that scientists (in the broad sense, which includes the arts and humanities, social sciences and natural/ technical sciences) have

\footnotetext{
${ }^{7}$ See Posner (2001), who reports on an earlier and similar analysis for the United States.
} 
joined the ranks. They may do so either in their capacity as specialists ${ }^{8}$, or else, unrelated to their area of specialisation, in their capacity as critically thinking human beings ${ }^{9}$.

Without in any way criticising the second way of being critical, it has long seemed to me that nowadays the 'being critical'-in' the sense of uncovering false images in and about what we do, mean and say--has to be part of, rather than only a comment on, at least some share of the researcher's activities. In other words, it cannot be kept out of how and what we do as specialists in our subject fields. Of course, there are big differences between disciplines depending on what their objects and methods of study may be, and how directly they interfere with socio-cultural reality, for to the extent that they have a bearing on our societies and our cultures, being critical matters. The assumed position of the pure critical intellectual outside scientific and technological production, and of the critical activity as a comment on what others 'do', appears to me to be less feasible than it ever may have been.

We shall describe one form of a critical discourse in my own area of linguistics and translation studies, in order to illustrate how the general property of 'being critical' may be translated into methodological questions inside an academic discipline. ${ }^{10}$ More specifically, we shall review a debate about schools of linguistics, formulate a thesis about basic types of orientation in the study of natural language, then characterise the opposing schools identified in the debate, before explaining how such characteristics translate into specific methodological orientations in studying language. At the end of this section, we shall argue that if we evaluate the two orientations in the study of language against the aim of being socially responsible and being critical, one of them is clearly more suitable than the other.

\footnotetext{
${ }^{8}$ For example (Weizenbaum 1976, 2001) for computer science and artificial intelligence, (Bourdieu 1991), (Negt 2001) for sociology, (Eagleton 1996) for literary studies, (Halliday 1967); (Halliday and Martin 1993) for linguistics.

${ }^{9}$ For example, see Chomsky (2000) and his numerous political writings.

${ }^{10}$ See Steiner $(1996,2001)$ for more detail on this. Extended parts of section three of this paper are drawn from the 1996 paper.
} 
Controversies in the course of the 1990s between different approaches to language (Beaugrande 1994; Jäger 1993; Grewendorf 1994; Bierwisch 1993) were, in our view, part of a wider debate about different ways of scientific theorizing (Weizenbaum, 1976; Heintz, 1993; Wajcman, 1994; Braverman, 1974; Bijker et al, 1987; Ahrweiler, 1995; Marx n.d.; Altvater, 1992; Negt 2001). The aspect of the debate that we focus on here is that of what is, and what should be, the responsibility of the scientific community for the effects of scientists' work, directly and indirectly, once that work is realised in some form of technology. The terms 'Chomsky-Theory' and 'Mead-Theory' are taken from a debate between Jäger (1993), on the one hand, and Bierwisch (1993) and Grewendorf (1993), on the other, later followed by a whole series of further contributions from a range of perspectives.

Jäger's main thesis $(1993,79)$ is that the history of linguistics over the past two hundred years (at least) can be seen as that of a mainstream, which he designates 'ChomskyTheories', and that marginalized an older position, or'Mead-Theories' (taking the names of Chomsky and Mead as the defining labels for these trajectories). In the progress of these theoretical developments, the object of inquiry, language, has been more and more eroded and specialized, until in the present time the term no longer supports the unity of one discipline or Sprachwissenschaft. Language, in all of its interrelationships with culture, society and history, thus disappears from the agenda, being reduced to a technical and biological/psychological mechanism.

Bierwisch (1993) responds to Jager's thesis by arguing that it completely misrepresents the essence of the Chomsky-paradigm and its historical context, has itself nothing to contribute to a serious study of language, and leads to incompetence in formal and technological modelling of processes associated with language.

Debates of this kind can be understood as re-instantiations of an older and more general debate between logic/philosophy-oriented and rhetoric/ethnography-oriented approaches to language study. In modern times, the opposition between rationalist and empiricist 
seems to be based on the same general discussion, as does the opposition formalist versus functionalist, at least in many cases. In the present paper, we would like to argue that yet another pair of headings under which debates are currently conducted is the one of 'technologically-oriented theories' versus ‘socially-oriented theories'. What remains to be seen is whether the opposition 'Chomsky-Theory' versus Mead-Theory' can be mapped one-to-one onto the 'technologically-oriented and socially-oriented' opposition, and whether it is the socially-oriented variety alone that offers a discursive space to critical intellectuals.

Let us begin by formulating briefly a thesis before moving on to a consideration of examples. At the end of this chapter, we shall evaluate types of linguistic theorizing relative to the goals of being critical and of being socially responsible. We assume that two basic orientations can currently be identified in the study of natural language, which we shall label ‘technologically-oriented' (type 1) versus ‘socially-oriented' (type 2). ${ }^{11}$ Technologically oriented theories structure their discourses after the model of the technical disciplines and/or formal and philosophical logic. They represent a rationalist and logic-oriented paradigm. Socially oriented theories structure their discourses after the model of the social sciences, rhetoric or descriptive grammar. They represent a more empiricist and rhetorically oriented paradigm.

The assumption of basic types of orientations in linguistics is shared by many people in the field. Type 1 above would include Chomskyan, but also most other schools of formal linguistics. Type 2 would include Prague, Czech, British, Dutch and West-Coast Functionalism, but also substantial orientations in Cognitive Grammar.

\footnotetext{
11 These are not the only types of approaches to natural language. In particular, type 2 above is not identical to approaches deriving from or situated in traditional philology and hermeneutics, which represent an important third type (3).
} 
We would like to suggest some general characteristics of our two categoriestechnologically oriented and socially oriented — before considering some of their realizations in terms of the methodological characteristics of distinct linguistics schools :

- Breadth of coverage: Theories and models of type 1 tend to take a highly specialized and restricted view on what constitutes a scientifically legitimate share of their object of study. In linguistics, their approved areas of study are clause syntax, formal (model theoretic) semantics, phonology and phonetics, and within all of these the focus is on competence rather than performance, i.e. idealized knowledge rather than instantiation of that knowledge.

- Specialization and formalization of methods: Within approaches of type 1 , nonformal methods are held to be unscientific. Methodology and terminology tend to be highly specialized and require education and socialisation into the corresponding academic communities. The distance to everyday knowledge is considerable and tends to increase. Theories of type 2 adopt a more cautious approach to formal methods, allowing methods from non-formal linguistics, as well as traditional and modern rhetoric. They, too, go through cycles of increasing specialization in their development, yet are based on greater breadth of coverage and on a continuous confrontation with relatively 'rich', i.e. natural, data.

- Orientation towards knowledge as an instrument of dominance vs. an instrument of emancipation: Approaches of type 1 have a tendency to generate and apply highly specialized and relatively inaccessible knowledge and therefore lend themselves easily to discourses of exclusion and social dominance. The institutional environment of approaches of type 1 is sometimes elitist. Approaches of type 2 have a tendency to generate and apply knowledge as a relatively accessible instrument of social action; the institutional environment is often nonelitist and open.

- Orientation towards neighbouring disciplines: Type 1 approaches see themselves as ‘sciences' (Grewendorf, 1994), or as related to, or even part of, cognitive science and psychology (see Edelman, 1992). In their contacts to philosophy, links are established with logic, and analytical and formal philosophy, rather than 
with more rhetorically or historically oriented fields in philosophy. The typical professional profile of graduates is in research, or, in the few areas where that stage has so far been reached, development. Type 2 approaches have stronger links in interdisciplinary contexts with the social sciences and pedagogy, although significant interdisciplinary work has been underway for a considerable time between Prague, Dutch, and British functionalism and computer science, for example in computational text generation. Within philosophy, links are sought with rhetoric, speech act theory and related areas. The typical professional profile of graduates is, apart from research, oriented towards areas such as language teaching, intercultural communication, or translation.

- Role of application: Type 1 approaches emphasize their status as 'theoretical', rather than 'applied', and the assumed borderline between these two orientations is sharp and rigid. Type 2 approaches tend more towards a dialectical view of the relationship between theory and application with the borderline between these fields being assumed to be continuous and gradual, rather than sharp and categorical.

- Life span of (versions of) theories: The life span of (versions of) a theory within approaches of type 1 tends to be short. Chomskyan linguistics, for example, has seen four substantially different versions of theories of syntax and language over the last 45 years. Such life spans are usually longer in the case of theories of type 2, which is, of course, partly a consequence of the fact that these latter theories do not, or not without reservations, subscribe to the corresponding 'hypotheticodeductive' view of progress from one (version of) a theory to the next.

Approaches of type 1 largely exemplify a perspective on science and technology in which theory is far removed from application, without responsibility for that application. Chomsky himself seems to share this uncritical view of science (Grewendorf 1994, 393) — quite a remarkable position in view of the fact that his views on politics in general are anything but uncritical (Chomsky, 2000, for one of numerous examples). He is thus a 
prime example of an outstanding intellectual who is critical in one context, yet extremely uncritical in the other.

After considering characteristics of types of linguistic theories, and after looking at some methodological consequences of these characteristics, let us suggest a few implications for evaluations of theories of language, intercultural communication, and translation in particular. We believe that these implications form part of a critical perspective within our discipline.

Models of language processing, if they are to provide us with instruments to effectively influence the process of the social construction of technological systems in the area of multi-lingual NLP, have to contain significant elements that facilitate an understanding of probable effects of those technologies. What is of interest here are the influences on the entire system of linguistic activities of participants in the processes concerned, rather than only influences on a few isolated parameters. A certain breadth of coverage, as well as inter- and trans-disciplinarity, are thus important.

The process of a responsible social construction of technologies will derive little meaningful input from models that:

- are overspecialized and drastically reduced in their perspective on their object of study, i.e. language and translation;

- are dominated in their view of the object of study and their choice of methods by questions of formalizability and deductive reasoning of a restricted kind (as in 'formal linguistics');

- largely exclude the social sciences from their interdisciplinary discourse;

- conceive of their role as distinctively 'theoretical' rather than 'applied'.

A constructively critical and socially oriented approach to the social construction of technological systems has to: 
- come from inside the disciplines concerned and therefore involve the responsibility of researchers, developers and teachers, rather than being added on to the core process of construction as a purely reflective exercise in interpretative discourse. A ‘black box approach’ to the evaluation of technological systems, which is usually characterized by the non-participation of the relevant research communities, is highly problematic both in terms of insights to be gained and in terms of effective influence;

- be allowed to exert effective social and political influence, rather than being assigned the role of a non-influential discourse about different ways of making a pre-existing technology maximally acceptable to users and consumers;

- take the form of an 'early intervention' in all stages of the process of the social construction of a technological system.

Even at present, when for example systems for fully automatic translation are more a research activity than a productive force on the market and in relevant communication processes, and when their application as systems for 'raw translations' is still rather tentative than wide-scale, these very immature technologies already have three types of negative effects on people engaged in translation professionally:

- The quality of the final product in a process in which machine-generated raw translations are used and post-edited may, in many cases, be markedly inferior in quality to a human translation. However, there are lines of argumentation in and around the relevant industries and research communities according to which the large-scale acceptance of such texts is advocated as one way of making a very immature technology acceptable for reasons of 'efficiency'. That type of argumentation should not be acceptable in a responsible process of technology construction.

- The space of creativity and control which is constituted by the choices a human translator makes when producing a text in the target language is severely reduced and re-structured by bringing into it a machine-generated raw translation as a first stage. The consequences are that the quality of the result suffers (see above) and 
that the process of translation becomes psychologically unsatisfying and demotivating.

- There is already a popular discourse, especially in funding agencies, parts of the 'Natural Language Processing' research community and in a few sectors of industry, through which the human capacity for translating is becoming de-valued and made available at cheaper prices. Advertising and marketing strategies of companies offering machine translation - systems, together with unrealistically optimistic announcements of high-performance systems by the research and development communities, combine to create the impression that translation is or will be, at this point in time or in the very near future, a scientifically wellunderstood and technologically controllable process. As a result, the human translation capacity becomes de-valued and underestimated. This may be a trend that lies behind some of the observed processes of under-financing both in terms of salaries and in terms of other forms of material support for translating as a social activity.

None of the negative effects just postulated appears unavoidable, yet such effects may well increase in strength if the process of technology construction in the areas of translation, and to a lesser extent, multi-lingual text production, continues in its present socially irresponsible and in that sense unintelligent way.

In considering the implications of what we have said, we cannot focus on computational technologies exclusively, or even predominantly. We have to develop a perspective on processes such as translation and multi-lingual text production both in their specifically technological and non-technological realizations. It has been apparent for a considerable time that those areas of productive activities that are 'taylorized'12 and fractionated lend themselves most easily to mechanisation. The predecessor of the highly mechanized, 'paperless' and de-populated office is the integrated and taylorized secretaries' pool of

\footnotetext{
${ }^{12}$ That is, treated in the compartmentalised or assembly line method of production pioneered by the American industrialist FW Taylor, that came to be known as Scientific Management
} 
earlier decades. The predecessor of the de-qualified, de-motivated and underpaid posteditor of machine-produced raw translations may well be the highly taylorized translators' department in big institutions or companies. A productive criticism of aspects of developing technologies will therefore have to involve a re-consideration of working practices in the area concerned, in both their technological and non-technological aspects.

We have, in the current section, discussed some mutual influences between professionalism, specialisation and intellectual life. Using linguists as a relevant group of specialists as an example, we have attempted to show how specialisation on the one hand, and being socially oriented, concerned and critical on the other, do not necessarily exclude (nor necessarily include) each other. We have also attempted to identify properties of 'concerned' and 'critical' approaches for that field. The intellectuals referred to here (have to) accept specialisation and professionalisation as necessary forms of existence. And this very specialisation and professionalisation gives them some degree of freedom from more unpleasant, alienating types of labour. At the same time, it ties them into the ideological systems of the institutions they are working for, and thus, as it were, reduces to varying degrees the critical edge of their statements. This latter constraining characteristic of their intellectual condition is certainly deplorable, but has, to varying degrees, always and necessarily been part of existence for the overwhelming majority of intellectuals. The implication in processes of specialisation does not in itself prohibit a critical perspective, I believe. However, it may reduce it, sometimes to the extent of making it almost non-existent. Yet even more pressing is the question of whether there are elements and properties of the intellectual process itself that are either constraining or else enabling for intellectuals to be 'critical' or 'concerned'. Some of these elements and properties will be addressed in the final section.

What appears to be undesirable from a social perspective-and has to be clearly made visible by a critical discourse-is the fact that an extreme rationalist orientation exists in some of the social sciences and humanities, which treats human knowledge and human language as individual (i.e. non-social), as thoroughly and exclusively representable 
through formal methods, and thus as amenable to existing technologies without any view to the context in which knowledge and language are situated. If this rationalist orientation joins forces with the 'natural' flow of capital investment into technology, rather than into social and human relations, this rationalism will contribute significantly to already existing trends to marginalize social man/woman out of the perspectives of both science and technology. That process started not later than modern capitalism, but has gained significant momentum in the past decades. A socially oriented, and thus socially committed, theory of language is an expression of counteracting forces in the fields of education and intercultural communication. But in addition to being socially oriented, it has to practice extreme care in maintaining a critical and self-critical stance, in order to avoid the dangers of rigid dogmatisms that have unfortunately disfigured-all too frequently_originally critical approaches intellectually.

\section{On the Possibility of a Critical Perspective}

After illustrating in some detail how elements of a critical and intellectual perspective might manifest themselves within the particular field of theories of language and of natural language processing technologies, we shall broaden our perspective into a wider set of questions relating to the role of the critical intellectual, in German (and other?) contexts. Our two questions here will be where we anchor value judgements, and our ethics, on the one hand, and whether there are forces driving the development of our cultures and societies, sources with which we can, however partially, identify and align ourselves in order to give direction to socio-cultural development.

Our first question revolves around the notions of values and ethics. Do we assume that the role of the critical intellectual is inherently connected to some systems of values, either in the sense of the enlightenment, and/or Marxism, and/or some other system of ethics. Or do we believe that the position of a critical intellectual could be defined without any recourse to some system of norms about what constitutes a 'good life'? Is there something like 'truth', 'progress' or 'justice', other than what is successful on the market in the sense of having a high exchange value? Is there a kind of bootstrapping 
process by which human cultures can derive norms out of their socio-cultural existence without a metaphysics?

Ever since classical times, the notion of Kritik has involved the judgement of some discovered 'truth'13. The judgement, however, was usually assumed to be operative against a given system of absolute norms. It may be seen to be a feature typical for modernity that these norms themselves can become objects of Kritik. Kant's Kritik der reinen Vernunft and numerous writings in that tradition have corroborated this again and again, as has been the case with Hegel, Marx, and many others. But even though specific systems of norms became the objects of Kritik, the critical activity itself was not separated from a judgement based on a normative ethics. And even in the twentieth century, normative judgements by critical intellectuals were seen as anchored in the specific position of intellectuals and their capacity-and obligation-to recognize, formulate and defend non-particularistic ethics (Bourdieu 1991, 17, 46; Negt, 2001). (Neo-)Marxists, in particular, have often criticised variants of postmodernist philosophical discourses for failing to recognise and aim towards a fulfilment of such capacity and obligation (e.g. Habermas 1988, 390ff; Eagleton 1996, 131ff).

It appears to me that in order to be critical, we have to assume that there is a perspective from which distortions of our picture of realities become visible, and others from which they don't. These would be perspectives that demand an ultimate respect for the intrinsic value of the human being, and which oppose the market-driven ideology that makes everything into a Tauschwert/exchange value that can be realised on the market. The dignity and value of the human individual is something that cannot be priced and that commands the highest respect in itself. Societies, cultures and ideologies of whatever type that do not respect this have to be exposed through the process of critique. Yet, the plural that we used when talking about 'critical perspectives' indicates that there is no single such position; several different positions at least are possible, and, indeed,

\footnotetext{
${ }^{13}$ See via inveniendi versus via iudicandi in the writings of Cicero and Quintillian (Krings et al. 1973: 810ff).
} 
necessary in order to derive knowledge out of differences and, more strongly, contradiction. Furthermore, in order to remain critical, we need the ability to judge developments by something other than success on the market. In other words, we need to postulate a primacy of some form of politics (in a generalised sense) over economicswhich does not in any way imply, of course, a disregard for the importance of a system of production or distribution as a basis for the life of a society and as a system for systematic feed-back about our actions in the socio-economic sphere. These positions, conjointly, are likely to encompass a fundus of important values - which is not the same as exchange values - and norms that, through a long process of critical investigation, provide the notions of 'truth', 'progress' or 'justice' which we need as a basis of that same process. And it is only through the elaboration of such notions that we can differentiate the critical intellectual from the ideologue, on the one hand, who argues for particularistic interests (Partikularinteressen) only, and from the mandarin on the other, who does not practice Kritik, because it would endanger the privileges derived from his or her association with the agencies in power (Scheidel 2002, 5ff; Lepsius 1964). Some contemporary postmodernist victimisation discourses concerned with identity positions have moved from the position of the ideologue to that of the mandarin without even so much as touching on a critical perspective_-and not least of all, because the necessity of some widely valid ethics was thought irrelevant or even harmful.

Our second question in this section is whether there are 'driving forces' for socio-cultural processes that motivate change, and, to use a more teleological term, evolution. If we make the crucial assumption of some truth, or at least non-falseness that we can recognise through the critical process, and if we assume that there will be perspectives from which such a critical process becomes possible, then such perspectives must in some sense become knowable, and criticisable, in the sense of distinguishable from other perspectives in an epistemological sense. Is there something like driving forces in sociocultural systems that motivate change (and evolution?) in societies, and cultures, and, by association, with which we gain insight into 'true' rather than 'false' relationships in reality? And do these driving forces leave traces in representations of realities that we can 
use as clues for points of access to knowledge, however imperfect and historically limited that knowledge may be?

Several formulations of hypotheses about such driving forces have been elaborated into philosophical systems. One important driving force is that of the relationship of contradiction, either between entities, and relationships such as means of production versus relationships of production (Marx n.d., Negt 2001), or between systems and their environments in general systems theory and cybernetics, to name two candidates. Another important epistemological category is that of contradictions between our hypotheses about some aspect of reality, and empirical reality, or between what ought to be the case, in an epistemic sense of ought to, and what is. The first set of contradictions would be driving forces for socio-cultural systems; the second would be driving forces for our active investigation in order to resolve the contradictions we notice. Both of these are epistemologically important as possibilities of learning, and of avoiding falseness. This category of contradiction is in no way exhausted by the category of difference as currently debated (Hegel 1951: 61).

There appear to be important implications for the role of the 'critical intellectual' if we assume an important role of contradictions in the critical process. If the crucial ability to discover contradictions involves human activity, and if this activity is productive, reproductive, but in both senses social activity, then the potential of being 'critical' arises out of participation — rather than only out of passive reflection upon-critical activities. This process thus brings us in contact — and conflict—with crucial socio-cultural agents and agencies. We have attempted to exemplify in our discussion of types of theorising and modelling in the area of natural language technologies above, what some of the issues may be in one particular instantiation.

Beyond possibilities of discovering and critique-ing/ distinguishing falseness from truth, we need systems of ethics and norms that are guided by some idea of a good society, just society - and these we can only obtain from what is best in the humanistic elements of 
human belief systems across cultures, including science, religion, and art. These ethics, an emergent property of processes of human activity, are preconditions and consequence of processes of critique. We thus obtain driving forces for our critical activity of a different nature, arising out of contradictions between what we observe empirically, and what we believe ought to be the case according to our ethics. Critical activity has to be grounded in a desire to guarantee a maximally worthy (würdig) form of existence for human beings - and in the diagnosis that counter to the claims of the ideologue and of the mandarin, this existence cannot arise out of the interests of particularistic groups; nor is it in reality guaranteed by the existing order.

Let us end with a conclusion that critical intellectuals — in Germany and elsewhere-have usually subscribed to, which is that states, such as Germany, may be historically contingent contexts, but nothing more, for intellectuals. Even cultures and societies, though less rigidly fenced into boundaries than states, can be roots and crucial contexts of development, but never the boundaries and exclusive discursive habitat for critical intellectuals, even less than for others. Finally and most importantly, just as there never were, and still aren't, nation-states that can legitimately claim to be the exclusive home of critical intellectuals, so there are no sociological spaces that can lay claim to ownership of the epithet 'critical'. There is no necessary connection between being an intellectual sociologically and being critical, ${ }^{14}$ for the critical mind nowadays has every reason to reject being imprisoned in any space—-be it geographical or otherwise.

\section{Reference List}

Ahrweiler, P. 1995, Künstliche Intelligenz-Forschung in Deutschland. Die Etablierung eines Hochtechnologie-Fachs, Volume 114 of Internationale Hochschulschriften, Waxmann, Münster and New York.

Altvater, E. 1992, Der Preis des Wohlstands, Verlag Westfälisches Dampfboot, Münster. Beaugrande, R. de 1994, 'Function and form in language theory and research. The tide is turning', Functions of Language, 1(2), 163-200.

Bierwisch, M. 1992, 'Grammatikforschung in der DDR: Auch ein Rückblick', Linguistische Berichte, (139), 169-81.

${ }^{14}$ As is argued very convincingly by Honneth (2002). 
1993, 'Ludwig Jägers Kampf mit den Windmühlen - Anmerkungen zu einer merkwürdigen Sprach(wissenschafts)verwirrung', Zeitschrift für Sprachwissenschaft, 12(1) 107-112.

Bijker, W. \& Hughes, T. \& Pinch, T., (eds.), 1987, The Social Construction of Technological Systems, MIT Press, Cambridge/ Mass.

Braverman, H. 1974, Labor and Monopoly Capital: The Degradation of Work in the $20^{\text {th }}$ Century, Monthly Review Press, New York.

Bourdieu, P. 1991, Die Intellektuellen und die Macht. Hg. v. Irene Dölling, VSA-Verlag, Hamburg.

Chomsky, N. 2000, Rogue states: the rule of force in world affairs, The South End Press, Cambridge, Mass.

Eagleton, T. 1996, The illusions of postmodernism, Blackwell, Oxford.

Edelman, G. 1992, Bright air, brilliant fire: on the matter of the mind. Harper Collins, New York.

Emmerich, W. 2001, 'Deutsche Schriftsteller als Intellektuelle. Strategien und Aporien des Engagements in Ost und West von 1954 bis heute', in Zeitschrift für Literaturwissenschaft und Linguistik 124, 28-46.

Grewendorf, G. 1993, 'Der Sprache auf der Spur: Anmerkungen zu einer Linguistik nach Jäger Art'. Zeitschrift Sprachwissenschaft, 1(12), 113 -132.

1994, 'Interview with Noam Chomsky: Notes on Linguistics and Politics', Linguistische Berichte, 153, 386-95.

Habermas J. 1988, Der philosophische Diskurs der Moderne. Zwölf Vorlesungen. Suhrkamp, Frankfurt am Main.

Halliday, M. A. K. 1967. Grammar, society and the noun, H.K. Lewis and Co., London. Halliday, M.A.K. and Martin, J.R. (eds.), 1993, Writing Science, Falmer Press, London. Hegel, Georg Wilhem Friedrich. 1951. Wissenschaft der Logik, 2. Teil. Leipzig: Meiner Verlag

Heintz, B. 1993, Die Herrschaft der Regel. Zur Grundlagengeschichte der Computer, Campus Verlag, Frankfurt.

Hegel, G.W.F. 1951, Wissenschaft der Logik, 2. Teil, Meiner Verlag, Leipzig.

Honneth, A. 2002, 'Die mythischen Mächte zerstören. Gesellschaftskritik im Zeitalter des normalisierten Intellektuellen’, in: Neue Zürcher Zeitung, Internationale Ausgabe Nr. 57 9/10 März 2002, $49 f$

Hopkins, A.G. (ed.), 2002, Globalization in World History, Pimlico, London.

IASL 2002, Internationales Archiv für Sozialgeschichte der deutschen Literatur 2002, see http://iasl.uni-muenchen.de [Accessed 2 January 2002]

Jäger, L. 1993, 'Language, whatever that may be. Die Geschichte der Sprachwissenschaft als Erosionsgeschichte ihres Gegenstandes', in Zeitschrift für Sprachwissenschaft, 12(1), 77-106

Krings, H. Baumgartner H. M. \& Wild, Ch. (eds.) 1973, Handbuch philosophischer Grundbegriffe. Bd. 3. Kösel Verlag, München.

Lepsius, M. R., 1964, 'Kritik als Beruf. Zur Soziologie der Intellektuellen.’ in: Kölner Zeitschrift für Soziologie und Sozialpsychologie 16, 75-91.

Maas, U. 1973, Grundkurs Sprachwissenschaft I - Die herrschende Lehre, Volume 1424 of Taschenbücher der Wissenschaft. 2nd. Ed., List, München, 
Marx, K. n.d., Das Kapital. Dietz Verlag, Berlin.

Mittenzwei, W. 2001, 'Die Intellektuellen'. Literatur und Politik in Ostdeutschland von 1945-2000. Faber \& Faber Verlag, Leipzig.

Negt, O. 2001, Arbeit und menschliche Würd, Steidel, Göttingen.

Posner, R. A. 2001, Public Intellectuals: A Study of Decline: A Critical Analysis, Harvard University Press, Cambridge, Mass.

Ritter, J. and Gründer, K. (eds.), 1976, Historisches Wörterbuch der Philosophie. Wissenschaftliche Buchgesellschaft, Darmstadt.

Scheideler, B. 2002, 'IASL Diskussionsforum online Geschichte und Kritik der Intellektuellen. Einleitung in die Diskussion' in: IASL 2002

Steiner, E. 1985, 'The concept of context and the theory of action' in: Language and the nuclear arms debate, Chilton, P. (ed.), 1985, Frances Pinter, London, 213-230.

1991, A functional perspective on language, action, and interpretation, Mouton De Gruyter, Berlin and New York

1996, 'Systemic Functional Linguistics: a Chomsky-Theory or a Mead-Theory?' in: Proceedings of the Anglistentag 1995 in Greifswald. Klein, J. und Vanderbeke, D. (eds.), Niemeyer, Tübingen, 169-92

- 2000, 'Translation Evaluation: some methodological questions arising from the German translation of Goldhagen's 'Hitler's Willing Executioners', in: Discourse and the Community. Ventola, E. (ed.), 2000, Gunter Narr Verlag, Tübingen, 291307.

2001, 'Arbeitnehmereinfluss auf Entstehung und Funktion neuer Informationstechnologien im Bereich der Interkulturellen Kommunikation’ in: Kooperativ forschen. Meister, H. und Roßmanith, B. (eds.), 2001, Röhrig Universitätsverlag, St Ingbert, 223-34.

Steiner, E., Schmidt, P. and Zelinsky-Wibbelt, C. (eds.), 1988, From syntax to semantics - insights from machine translation, Frances Pinter, London.

Steiner, E. \& Yallop, C. (eds.) 2001, Exploring Translation and Multilingual

Textproduction: Beyond Content. Series Text, Translation, Computational Processing. Mouton de Gruyter, Berlin, New York.

vanDijk, T. A. 1993, Elite Discourse and Racism. Sage, London.

Wajcman, J. 1994, Technik und Geschlecht. Die feministische Technikdebatte. Campus

Verlag, Frankfurt etc.

Weizenbaum, J. 1976, Computer power and human reason, W.H. Freeman and Company, San Francisco

—. 2001, Computermacht und Gesellschaft. Suhrkamp, Frankfurt/Main.

Winograd, T. \& Flores, F. 1986,Understanding computers and cognition: a new foundation for design, Ablex, Norwood, New Jersey. 